\title{
Impact of Preoperative Video Education for Cataract Surgery on Patient Learning Outcomes
}

\author{
This article was published in the following Dove Press journal: \\ Clinical Ophthalmology
}

\author{
C Ellis Wisely' \\ Cason B Robbins (D) ${ }^{2}$ \\ Sandra Stinnett' \\ Terry Kim' \\ Robin R Vann (D) \\ Preeya K Gupta' \\ 'Duke University, Department of \\ Ophthalmology, Durham, NC, USA; \\ ${ }^{2}$ Duke University, School of Medicine, \\ Durham, NC, USA
}

Correspondence: Preeya K Gupta

Duke University Eye Center at Page

Road, 4709 Creekstone Drive Suite 100,

Durham, NC 27703, USA

$\mathrm{Tel}+1$ 919-660-5234

Email preeya.gupta@duke.edu
Purpose: To assess the effect of an educational video on 1) patient knowledge about cataract surgery, 2) patient perception of preoperative assessment visit quality, 3) face-to-face time with the surgeon, and 4) choices regarding premium intraocular lenses (IOLs) or laser-assisted cataract surgery (LACS).

Setting: Eye clinic in an academic medical center.

Design: Prospective survey of patients who randomly viewed or did not view an educational video.

Methods: Patients of three cataract surgeons completed a survey during cataract surgery preoperative visits. One group viewed an educational video about cataract surgery, while the other did not. All patients received their surgeon's typical preoperative counseling.

Results: A total of 101 patients were surveyed. Out of 101 patients, 58 viewed the educational video. Patients who viewed the video exhibited stronger learning outcomes; in particular, patients who viewed the video scored higher on cataract surgery educational assessments than those who did not $(83 \%$ vs $76 \%, \mathrm{p}=0.032)$, particularly on the assessment of postoperative visual expectations ( $98 \%$ vs $80 \%, \mathrm{p}=0.003)$. Differences in educational assessment scores between groups were not affected by which surgeon patients saw $(\mathrm{p}=0.807)$. Patients who watched the video were more likely to agree their surgeon provided quality explanations (93\% vs $74 \%$ strongly agreed, $\mathrm{p}=0.025)$ and trended toward greater perception the surgeon spent enough time with them $(\mathrm{p}=0.067)$. Video education did not affect face-to-face surgeon time with patients $(\mathrm{p}=0.212)$ or choices of multifocal IOLs $(\mathrm{p}=0.795)$, toric IOLs $(\mathrm{p}=0.321)$, or LACS $(\mathrm{p}=0.940)$.

Conclusion: Video education during preoperative cataract surgery assessments improved patient understanding of cataract surgery and perception of preoperative visits. Video education is easily integrated into preoperative visits and can enhance the preoperative experience.

Keywords: cataract surgery, video education, patient experience

\section{Introduction}

Cataract surgery is one of the most commonly performed medical procedures. Modern surgical techniques and advances in technology have dramatically increased the safety of cataract surgery, but all surgical procedures carry benefits and risks that must be explained clearly to patients. A robust education and informed consent process for surgical procedures ensures patients are making empowered choices regarding their care. Purposeful preoperative education has been shown to increase patient understanding of surgical techniques and patient satisfaction. ${ }^{1,2}$ Prior surveys have determined patients are eager to know specific information about the risks and benefits of cataract surgery. ${ }^{3}$ In cataract surgery, 
quality preoperative education and counseling may be more closely correlated with patient satisfaction than medical outcomes. ${ }^{1}$ Presently, surgeons use many different educational approaches with minimal standardization of educational processes. ${ }^{4}$

In modern medicine, many patients seek detailed multimedia information online in preparation for their upcoming surgeries, and they often find information of inconsistent quality and accuracy. ${ }^{5}$ Some surgeons are incorporating multimedia presentations into their preoperative educational process. Specifically, a number of studies across surgical disciplines, including ophthalmology, have assessed the potential value of multimedia-assisted informed consent. ${ }^{6-11}$ Studies have shown that videoassisted informed consent may lead to better knowledge retention, ${ }^{10,12-14}$ increased patient satisfaction, ${ }^{14,15}$ and decreased clinic visit times. ${ }^{15}$ However, these approaches may not be harnessing the full potential of video education. While gaps in the educational process are certain to vary among surgeons, it has recently been demonstrated that surgeons are more likely to discuss the potential risks of cataract surgery than other issues such as lens choices. ${ }^{16}$ In the present study, we sought to investigate whether video education had an effect on patient knowledge of cataract surgery, patient satisfaction with the visit and provider, time spent with the provider, and premium product choices including premium lens implants or laser-assisted cataract surgery (LACS).

\section{Methods}

\section{Patient Selection}

Patients of ages 18-89 years presenting for cataract surgery preoperative assessment visits with any of three cataract surgeons (TK, RV, or PG) at the Duke Eye Center between July 1, 2018 and December 31, 2018 were presented with a survey (Appendix) with questions designed to assess particular patient learning outcomes regarding their education about cataract surgery and their feelings about the quality of their surgeon and their outpatient visit. This study was conducted with the approval of The Duke University Medical Center's Institutional Review Board (IRB). As no protected health information (PHI) was recorded for this study, our IRB determined our study qualified for a waiver of informed written consent. Survey participants did not complete consent forms. Surveys were completed at the end of the outpatient visit. Survey participants turned in the survey to the clinic staff at the end of the visit. The surgeon then completed the survey by answering three short questions (Appendix). During their preoperative assessment visits, patients were randomly chosen by clinic staff to view or not view an educational video about cataract surgery prior to their encounter with the surgeon. Clinic staff tasked with the assignment of patients to video or no video groups were not involved in the study design, data collection, or analysis. All patients received typical preoperative counseling provided as part of their surgeon's standard routine, and surgeons were masked regarding whether or not the patient had seen the video.

\section{Survey Development and Educational Video}

A 27-question survey was developed by adapting a previously published questionnaire for assessing patient knowledge of cataract surgery. ${ }^{9}$ Other survey themes were developed after review of a survey developed by Shukla et al (2012) ${ }^{10}$ and the Clinician and Group Consumer Assessment of Healthcare Providers and Systems (CGCAHPS) survey (available at www.ahrq. gov/cahps/surveys-guidance/cg/index.html). The survey was written at a $7^{\text {th }}$ grade reading level. The $10-\mathrm{min}$ educational video was created by Rendia, Inc. (Baltimore, MD), and featured detailed information describing 1) benefits of cataract surgery including improvement in visual acuity and visual quality, 2) a comparison of steps of traditional and LACS (Illustrated via video screenshots in Figures 1 and 2) including astigmatism correction, the capsulorhexis, and nuclear division, 3) description of premium IOL choices including multifocal and toric lens implants, and 4) postoperative expectations including the need for postoperative eye drops, visual recovery timelines, and activity restrictions. The topical segments used to create the video were selected from a library of video clips (Rendia, Inc., Baltimore MD) and sequenced in a custom arrangement for the purpose of the study.

\section{Statistical Analysis}

Statistical analysis was performed using SAS/STAT software, Version 9.4 of the SAS System for Windows. Copyright (C) 2002-2012 SAS Institute Inc. For the 11question Cataract Surgery Knowledge portion of the survey, patients' responses were marked either as correct or incorrect or each question. A proportion of correct 


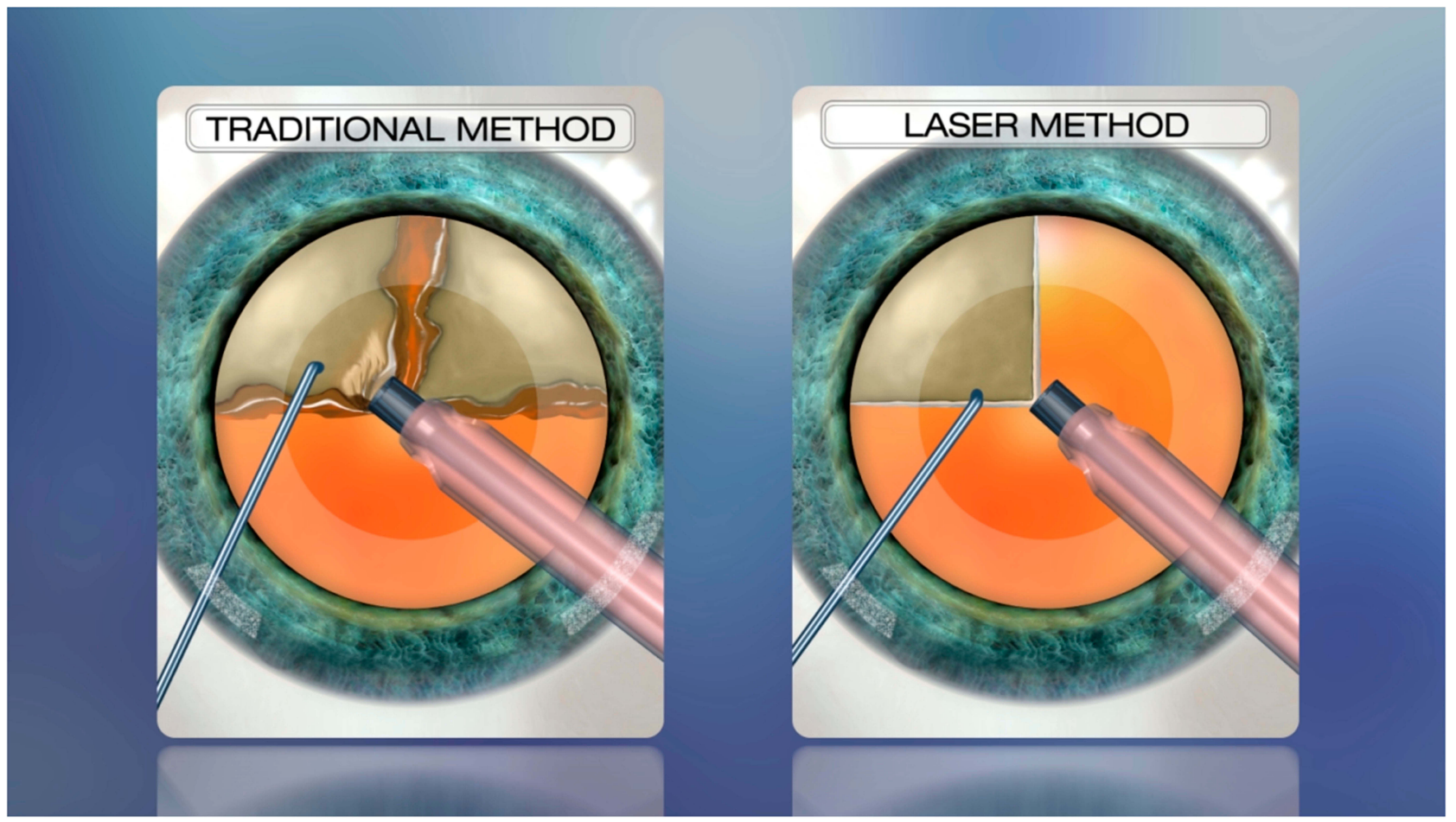

Figure I Screenshot from a portion of the educational video (Courtesy of Rendia, Inc. (Baltimore, MD)). This segment of the video illustrated the steps of traditional cataract surgery and laser-assisted cataract surgery (LACS).

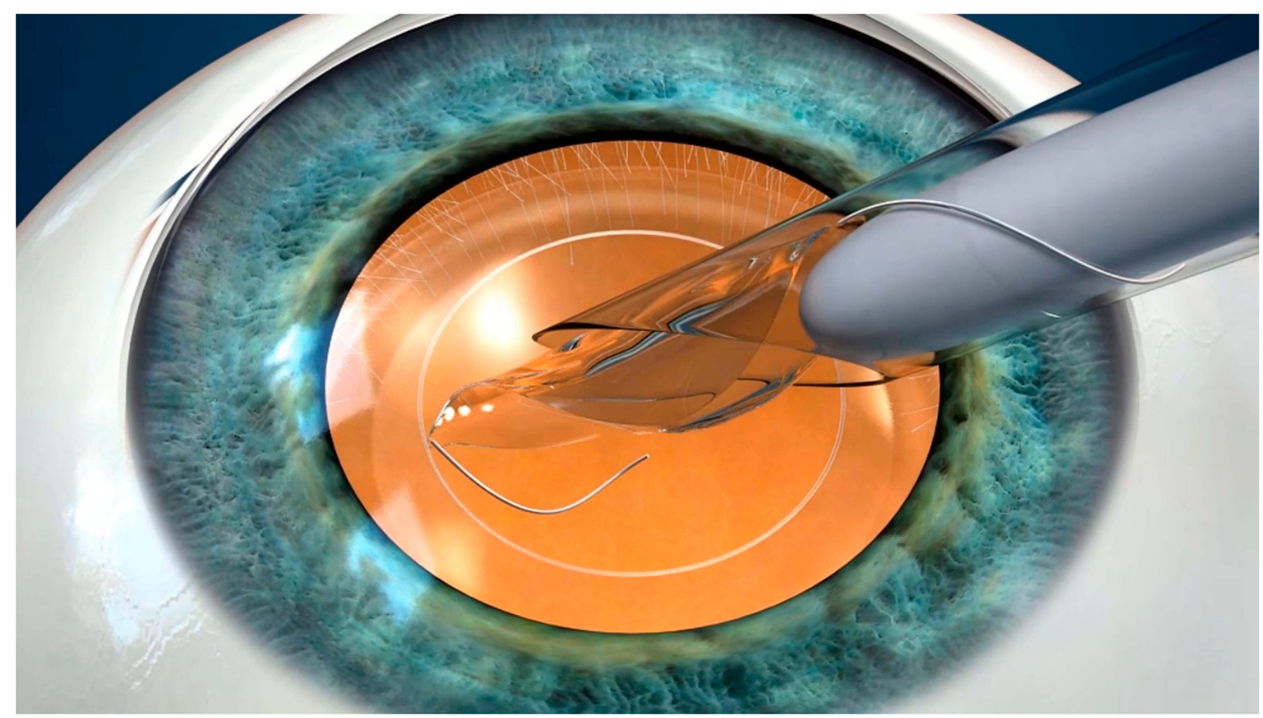

Figure 2 Screenshot from a portion of the educational video (Courtesy of Rendia, Inc. (Baltimore, MD)) demonstrating injection of the intraocular lens.

responses for the 11-question test was then calculated for each patient. Analysis of Total Knowledge Assessment Scores, as shown in Table 1, used these values. Fisher's exact tests were used to assess the significance of the difference between groups for individual knowledge assessment questions. The Wilcoxon rank-sum test was used to compare the overall knowledge assessment tests between groups. Fisher's exact tests were used to compare visit quality assessments and lens choices between the two groups. A Wilcoxon rank-sum test of the difference between medians was used to compare the time spent with the patient between the two groups. For the total knowledge assessment, a two-way analysis of variance was used to examine the combined effects of video and 
Table I Summary of Cataract Surgery Knowledge Assessment

\begin{tabular}{|l|c|c|}
\hline Survey Question & \multicolumn{2}{|c|}{$\begin{array}{c}\text { Correct Response Rate } \\
\text { (Mean (SD)) }\end{array}$} \\
\cline { 2 - 3 } & Video (n=58) & No Video (n=43) \\
\hline Total Knowledge Assessment Score & $0.83(0.16)$ & $0.76(0.20)$ \\
"Is it likely your vision will be completely clear the first day after surgery?" & $0.98(0.13)$ & $0.80(0.40)$ \\
"Where is the new artificial lens placed inside the eye?" & $0.89(0.32)$ & $0.76(0.43)$ \\
"How does one notice that one has 'cataract'?" & $0.93(0.33)$ & $0.88(0.26)$ \\
"Will an intraocular lens be needed to improve your vision after surgery?" & $0.67(0.47)$ & $0.54(0.50)$ \\
\hline
\end{tabular}

Notes: Results of the assessment of cataract surgery knowledge. "Correct Response Rate" refers to the proportion of correct answers to each question. "Total Knowledge Assessment Score" refers to the proportion of correct answers for the II-question multiple-choice and yes/no question test of cataract surgery knowledge. A complete list of the knowledge assessment questions can be found in the Appendix.

Abbreviation: SD, standard deviation.

surgeon. A term for interaction of the two variables was included to determine whether the difference between video groups differed by the surgeon.

\section{Results}

There were 101 patients included in the study; 58 patients viewed a 10-min educational video, and 43 patients did not

Table 2 Summary of Quality of Care Perceptions

\begin{tabular}{|c|c|c|c|}
\hline & \multicolumn{2}{|c|}{$\begin{array}{l}\text { Participant Responses } \\
\text { (n (\%)) }\end{array}$} & \multirow[t]{2}{*}{ p-value } \\
\hline & $\begin{array}{l}\text { Video } \\
(n=58)\end{array}$ & $\begin{array}{c}\text { No Video } \\
(n=37)\end{array}$ & \\
\hline $\begin{array}{l}\text { "My provider explained } \\
\text { information in a way that } \\
\text { was easy to understand." }\end{array}$ & $\begin{array}{c}\text { I: } 0(0) \\
2: 0(0) \\
3: 4(7) \\
4: 54(93)\end{array}$ & $\begin{array}{c}\text { I: } 0(0) \\
\text { 2: I (3) } \\
\text { 3: } 8(22) \\
\text { 4: } 28(76)\end{array}$ & 0.025 \\
\hline $\begin{array}{l}\text { "My provider spent enough } \\
\text { time with me." }\end{array}$ & $\begin{array}{l}\text { I: } 0(0) \\
\text { 2: } 0(0) \\
\text { 3: } 5(9) \\
4: 53(91)\end{array}$ & $\begin{array}{c}\text { I: } 0(0) \\
2: 2(5) \\
\text { 3: } 6(16) \\
\text { 4: } 29(78)\end{array}$ & 0.067 \\
\hline $\begin{array}{l}\text { "How would you rate the } \\
\text { quality of your care today?" }\end{array}$ & $\begin{array}{l}\text { I: } 0(0) \\
\text { 2: } 0(0) \\
\text { 3: } 0(0) \\
\text { 4: } 2(4) \\
\text { 5: } 56(97)\end{array}$ & $\begin{array}{l}\text { I: I (3) } \\
\text { 2: } 0(0) \\
\text { 3: } 0(0) \\
\text { 4: } 2(5) \\
\text { 5: } 34(92)\end{array}$ & 0.106 \\
\hline $\begin{array}{l}\text { "How comfortable do you } \\
\text { feel in your understanding of } \\
\text { your upcoming surgery?" }\end{array}$ & $\begin{array}{c}\text { I: } 0(0) \\
\text { 2: } 0(0) \\
\text { 3: I (2) } \\
\text { 4: } 8(14) \\
\text { 5: } 49(84)\end{array}$ & $\begin{array}{c}\text { I: I (3) } \\
\text { 2: I (3) } \\
\text { 3: I (3) } \\
\text { 4: } 6(16) \\
\text { 5: } 28(76)\end{array}$ & 0.195 \\
\hline
\end{tabular}

Notes: Results of the assessment of visit quality. I-4 scores indicate: I (strongly disagree), 2 (disagree), 3 (agree), 4 (strongly agree). I-5 scores indicate ratings with $\mathrm{I}$ being worst and 5 being best. There were six survey participants in the no video group who did not respond to this portion of the survey. receive video education. Table 1 compares the results of the cataract surgery knowledge assessments in patients who viewed and did not view the video. Patients who viewed the video $(n=58)$ scored higher on average on cataract surgery educational assessments than those $(n=43)$ who did not ( $83 \%$ vs $76 \%, p=0.032)$, particularly on assessment of postoperative visual expectations $(98 \%$ vs $80 \%, \mathrm{p}=0.003$ ). Results of other selected knowledge assessment questions from the questionnaire are compared between groups in Table 1. No other individual questions assessing knowledge of cataract surgery demonstrated a statistically significant difference between the video and no video groups. The difference in educational assessment scores between video and no video groups, in terms of total knowledge assessment score, was not different among surgeons $(\mathrm{p}=0.807)$. Patient education level, $45 \%$ $(n=45)$ with no college degree and $55 \%(n=56)$ with a college degree, did not have a significant effect on overall knowledge assessment scores ( $78 \%$ vs $82 \%, \mathrm{p}=0.383$ ).

In terms of the visit quality assessment as described in Table 2, patients who watched the video were more likely to state their surgeon provided quality explanations $(\mathrm{p}=0.025)$. Patients who watched the video also trended toward greater perception the surgeon "spent enough time" with them $(p=0.067)$. As demonstrated in Table 2, participants in both the video and no video groups had very positive perceptions of their care quality, with $97 \%(56 / 58)$ of patients who viewed the video and $92 \%$ (34/37) of patients who did not view the video providing the highest possible rating their care quality, $5 / 5$. There was no statistically significant difference in patient perception of overall care quality $(\mathrm{p}=0.106)$ between the two groups. Similarly, both groups reported strong feelings of understanding of their upcoming surgeries, with $98 \%$ (57/58) of patients who viewed the video and $92 \%$ (34/37) of patients 
Table 3 Summary of Intraocular Lens Choices

\begin{tabular}{|l|c|c|c|}
\hline \multirow{2}{*}{} & \multicolumn{2}{|c|}{$\begin{array}{c}\text { Participant Lens Choices } \\
\text { (n (\%)) }\end{array}$} & \multirow{2}{*}{ p-value } \\
\cline { 2 - 3 } & $\begin{array}{c}\text { Video } \\
(\mathbf{n = 5 8 )}\end{array}$ & $\begin{array}{c}\text { No Video } \\
(\mathbf{n}=\mathbf{4 3})\end{array}$ & \\
\hline Chose multifocal IOL & $7(12)$ & $3(7)$ & 0.795 \\
Chose toric IOL & $17(29)$ & $10(23)$ & 0.321 \\
Chose LACS & $34(59)$ & $23(53)$ & 0.940 \\
\hline
\end{tabular}

who did not view the video rating their comfort level at either $4 / 5$ or $5 / 5$ on a scale from 1 to 5 with 5 representing the highest degree of comfort. Thus, there was no statistically significant difference between the two groups in patient comfort with the upcoming surgery $(p=0.195)$. As mentioned in the Table 2 footnotes, six patients in the no video group did not respond to the survey questions used to create this table. As this survey was completed independently by patients without oversight from study personnel, it is unclear why certain items were incomplete. Video education also did not affect face-to-face time surgeons spent with patients $(\mathrm{p}=0.212)$, with a mean and standard deviation of time spent with surgeon 15.6 (8.1) and 13.3 (7.1) minutes in the video and no video groups, respectively. Finally, as represented in Table 3, there was a trend towards increased acceptance of premium cataract surgery choices with video education; however, this was not statistically significant (multifocal IOLs $(\mathrm{p}=0.795)$, toric IOLs $(\mathrm{p}=0.312)$, or LACS $(\mathrm{p}=0.940))$.

\section{Discussion}

As the population ages, cataract incidence is expected to double from 2010 to 2050 (24.4 million to 50 million), ${ }^{17}$ necessitating a markedly increased volume of cataract surgery over the coming decades. Thus, comprehensive strategies to streamline the perioperative care of patients with cataract surgery will be necessary to ensure continued patient satisfaction and proper informed consent. Technology is being increasingly utilized in outpatient perioperative surgical assessment to assist in patient education and informed consent. Studies have shown that specific presurgical counseling improves patient knowledge about cataract surgery, ${ }^{9}$ and decreases anxiety related to surgical procedures in various subspecialties, including ophthalmology. . $^{4,10,13-15,18}$ Technology has been used in a number of ways to increase the efficiency of the perioperative surgical visit for cataract surgery including educational videos and interactive computer-based tutorials. ${ }^{19}$
Recent work by Tipotsch-Maca et $\mathrm{al}^{10}$ and Zhang et $\mathrm{al}^{13}$ suggest that a preoperative multimedia-assisted informed consent procedure for cataract surgery improves information retention. Given these findings, we anticipated that a standardized, plain-language educational video would increase patient knowledge regarding cataract surgery, which our study confirmed. Our study supports the previous prospective survey results by demonstrating that video education may be especially helpful in educating patients regarding postoperative outcomes. ${ }^{13}$ Additionally, our study adds information about the patient experience in cases where video education is used, showing patients who underwent video education believed their surgeons explained things in a manner that was easy to understand and perceived their surgeons spent enough time with them during the assessment. Interestingly, the present study did not support that video education affects the selection of premium technology, such as lens choice or the choice of LACS. Future studies may investigate the impact of video education which includes a review of financial information surrounding the available technology options to elucidate the impact of cost on patient decision-making.

Patients have previously been shown to have an expectation-outcome discrepancy phenomenon regarding postoperative visual outcomes. ${ }^{20}$ Pager $^{20}$ reported that $60 \%$ of patients expected a perfect score on the Visual Function Index (VF-14) after cataract surgery, with an average expected VF-14 of 96.1 and an average achieved a score of 89.8. This phenomenon is mirrored in surgical patients broadly as evidenced by a review by Waljee et al, ${ }^{21}$ which found that across 60 studies of patient satisfaction and patient-reported outcomes, there was no consistent correlation between patient expectations and outcomes. In our study, patients who observed a perioperative video had an improved understanding of expected visual outcomes after cataract surgery (Table 1), suggesting that video education may help to alleviate the discrepancy between expectation and outcome regarding the postoperative visual course in ophthalmic surgery.

We also hypothesized that patients who observed a preoperative video might feel more satisfied with the care from their surgeon after their preoperative evaluations. Our findings suggest this may be true, as evidenced by the fact that patients felt their surgeon explained concepts more clearly if they had watched the video prior to a face-to-face encounter. We also hypothesized that watching a video would increase visit efficiency and allow providers to achieve similar education and satisfaction with decreased in-room visit time; however, there was no significant 
difference between the time the surgeon spent in the room between patients who saw the video and those who did not. This implies that, while video education is beneficial for patients regarding education and satisfaction, it does not necessarily increase the efficiency or length of time of the preoperative visit.

Limitations of this study include the lack of prior validation of our survey. We attempted to mitigate this issue using questions from previously published surveys and using simple language $\left(7^{\text {th }}\right.$ grade reading level average). Additionally, we assessed patients only at the preoperative visit, while the effects of our video education may have also had effects on the day of surgery or at the postoperative visit that were not evaluated.

\section{Conclusion}

Video education during preoperative cataract surgery assessments improved patient understanding of cataract surgery. Video education also affected patient perception of preoperative visits, particularly feelings about information quality. In our experience, video education is easily integrated into preoperative visits for cataract surgery evaluation and can enhance the preoperative experience and is a useful adjunct to traditional preoperative counseling between patients and their surgeons.

\section{Acknowledgment}

Previously presented at the American Society of Cataract and Refractive Surgery, May 2019, San Diego, CA, USA.

\section{Funding}

The authors received no funding for this research or for other related projects.

\section{Disclosure}

None of the authors have any relevant conflicts of interest related to this project.

\section{References}

1. Nijkamp MD, Nuijts R, van den Borne B, Webers C, van der Horst F, Hendrikse F. Determinants of patient satisfaction after cataract surgery in 3 settings. J Cataract Refract Surg. 2000;26(9):1379-1388. doi:10.1016/S0886-3350(00)00501-0

2. Pager CK. Randomised controlled trial of preoperative information to improve satisfaction with cataract surgery. Br J Ophthalmol. 2005;89 (1):10-13. doi:10.1136/bjo.2004.048637

3. Elder MJ. What patients want to know before they have cataract surgery. Br J Ophthalmol. 2004;88(3):331-332. doi:10.1136/bjo/2003.020453
4. Choi AR, Greenberg PB. Patient education strategies in cataract surgery: a systematic review. J Evid Based Med. 2018;11(2):71-82. doi:10.1111/jebm.12297

5. Bae S, Baxter S. YouTube videos in the English language as a patient education resource for cataract surgery. Int Ophthalmol. 2018;38 (5):1941-1945. doi:10.1007/s10792-017-0681-5

6. Evrard S, Mathoulin-Pelissier S, Larrue C, Lapouge P, Bussieres E, Tunon De Lara C. Evaluation of a preoperative multimedia information program in surgical oncology. Eur J Surg Oncol. 2005;31 (1):106-110. doi:10.1016/j.ejso.2004.09.019

7. Goldberger J, Kruse J, Kadish A, Passman R, Bergner D. Effect of informed consent format on patient anxiety, knowledge, and satisfaction. Am Heart J. 2011;162(4):780-785. doi:10.1016/j. ahj.2011.07.006

8. Sahai A, Kucheria R, Challacombe B, Dasgupta P. Video consent: a pilot study of informed consent in laparoscopic urology and its impact on patient satisfaction. JSLS. 2006;10(1):21-25.

9. Tipotsch-Maca SM, Varsits RM, Ginzel C, Vecsei-Marlovits PV. Effect of a multimedia-assisted informed consent procedure on the information gain, satisfaction, and anxiety of cataract surgery patients. J Cataract Refract Surg. 2016;42(1):110-116. doi:10.1016/ j.jcrs.2015.08.019

10. Shukla AN, Daly MK, Legutko P. Informed consent for cataract surgery: patient understanding of verbal, written, and videotaped information. J Cataract Refract Surg. 2012;38(1):80-84. doi:10. 1016/j.jcrs.2011.07.030

11. Schauer C, Floyd T, Chin J, Vandal AC, Lampen-Smith A. Video or verbal? A randomised trial of the informed consent process prior to endoscopy. N Z Med J. 2019;132(1489):57-68.

12. Moseley TH, Wiggins MN, O'Sullivan P. Effects of presentation method on the understanding of informed consent. Br J Ophthalmol. 2006;90(8):990-993. doi:10.1136/bjo.2006.092650

13. Zhang MH, Haq ZU, Braithwaite EM, Simon NC, Riaz KM. A randomized, controlled trial of video supplementation on the cataract surgery informed consent process. Graefes Arch Clin Exp Ophthalmol. 2019;257(8):1719-1728. doi:10.1007/s00417-01904372-5

14. Lin YK, Chen CW, Lee WC, et al. Educational video-assisted versus conventional informed consent for trauma-related debridement surgery: a parallel group randomized controlled trial. BMC Med Ethics. 2018;19(1):23. doi:10.1186/s12910-018-0264-7

15. Zhang Y, Ruan X, Tang H, Yang W, Xian Z, Lu M. Video-assisted informed consent for cataract surgery: a randomized controlled trial. J Ophthalmol. 2017;2017:9593631.

16. Henderson BA, Solomon K, Masket S, et al. A survey of potential and previous cataract-surgery patients: what the ophthalmologist should know. Clin Ophthalmol. 2014;8:1595-1602. doi:10.2147/ OPTH.S69133

17. National Eye Institute. Cataract Data and Statistics. National Institutes of Health. Last Updated July 2019; https://nei.nih.gov/eye data/cataract. Accessed July 23rd, 2019.

18. Ahmed KJ, Pilling JD, Ahmed K, Buchan J. Effect of a patient-information video on the preoperative anxiety levels of cataract surgery patients. J Cataract Refract Surg. 2019;45(4):475-479. doi:10.1016/j.jcrs.2018.11.011

19. Wollinger C, Hirnschall N, Findl O. Computer-based tutorial to enhance the quality and efficiency of the informed-consent process for cataract surgery. J Cataract Refract Surg. 2012;38(4):655-659. doi:10.1016/j.jcrs.2011.10.038

20. Pager CK. Expectations and outcomes in cataract surgery: a prospective test of 2 models of satisfaction. Arch Ophthalmol. 2004;122(12):1788-1792. doi:10.1001/archopht.122.12.1788

21. Waljee J, McGlinn EP, Sears ED, Chung KC. Patient expectations and patient-reported outcomes in surgery: a systematic review. Surgery. 2014;155(5):799-808. doi:10.1016/j.surg.2013.12.015 


\section{Publish your work in this journal}

Clinical Ophthalmology is an international, peer-reviewed journal covering all subspecialties within ophthalmology. Key topics include: Optometry; Visual science; Pharmacology and drug therapy in eye diseases; Basic Sciences; Primary and Secondary eye care; Patient Safety and Quality of Care Improvements. This journal is indexed on PubMed

Submit your manuscript here: https://www.dovepress.com/clinical-ophthalmology-journal
Central and CAS, and is the official journal of The Society of Clinical Ophthalmology (SCO). The manuscript management system is completely online and includes a very quick and fair peer-review system, which is all easy to use. Visit http://www.dovepress.com/ testimonials.php to read real quotes from published authors. 